\title{
Rachel Poliquin
}

\section{How To See A Magpie}

Joan B. Landes, Paula Young Lee, and Paul Youngquist, ed. Gorgeous Beasts: Animal Bodies in Historical Perspective. College Station: Penn State University Press, 2012. 258 pp. $\$ 49.95$ (hb).

A taxidermied magpie cocks its eye from the jacket cover of Gorgeous Beasts: Animal Bodies in Historical Perspective, the latest volume in the new Animalibus Series from Pennsylvania State University Press. Barely contained by a bell jar, the magpie perches above a mound of miscellaneous shiny things. The bird has the neutral pose of a natural history specimen; the bell jar suggests the embalmed nature of Victorian parlours. Yet the heap of scavenged trinkets helps us see the magpie as an individual, a sentient creature with particular tastes and preferences. Magpies are among the most intelligent animals. They are also one of the most aesthetically sophisticated. Hoarding its pearls and silver spoons together with safety pins and keys, the magpie has its own aesthetic tastes that defy humans' sense of value and worth. The magpie is part of Marc Dion's artwork Portrait of a Collector (2004), a title which evokes a collector's passion, personal value, and perhaps a touch of eccentricity. But which collector is on display? The magpie or the naturalist? Or perhaps the collector is the pervasive human desire to bottle up the rest of nature for our contemplation and enjoyment? Portrait of a Collector has no straightforward answers, and it is surely no coincidence that the editors of Gorgeous Beasts chose Dion's magpie, a scavenger, a trickster, a collector, a renowned mimic, and a dead bird under glass, as their envoy.

Animal studies is innately pandisciplinary, and the Animalibus Series seeks to explore the resplendent, tragic, and indispensable roles animals have and continue to play within human lives and culture. And with that mandate, Gorgeous Beasts succeeds beautifully. Edited by Joan B. Landes, Paula Young Lee and Paul Youngquist, Gorgeous Beasts brings together nine essays by some of the most sophisticated voices within animal studies to explore the histories and desires shaping human encounters with other animals, both alive and dead. The volume delves into a fascinating range of topics from King Lear's call for civet musk to late Victorian elephant hunting to the collapse of the Grand Banks cod fishery, and animals are explored as fashion, fetish, hunted amusements, captive entertainments, farm power, eatibles, art objects, science specimens, national treasures, even lethal weapons. The volume concludes with a conversation between Dion, one of the most thought-provoking contemporary animal 
artists, and the editors about his work amidst our broader animal relationships. Part way through the discussion Dion comments that "art speaks best when it defies the simplicity of right and wrong and attempts to give voice to the complexity of ambivalence, melancholy, mourning, uncertainty, and the complex, irritated state in which we often find ourselves when the contemporary society fails miserably to fulfil its promise of rationality, in other words, the absurd" (170). The remark is equally applicable to animal studies. The questions most worth asking never have easy or straightforward answers. As with art, the best critical work destabilizes traditional narratives with ambiguity and paradox. And most poignantly, the best work asks readers or viewers to question their own sense of place within the world. Gorgeous Beasts asks all the right questions. Its animal bodies are provocative, unpredictable, and potent. Meticulously researched and eloquently argued with clear, accessible language, the essays incite a knowing that grows beyond the page and into our daily lives with other animals.

In their introduction the editors outline the difficulties at work in really seeing and connecting with animals. "Animals are never just there to be seen, felt, or known. History situates them. Culture appropriates them. Science defines them in one way, affection in another" (3). Seeing animals means seeing them through various long and thorny histories of representation which are shaped by the ever-shifting desires, fears, curiosity, and contradictions that color all our animal encounters. But like the magpie, animals are always more than objects of human contemplation and desire. After all, it is "bright and fecund bodies of beasts" that compel our desiring. Animals always exceed human reckoning because "animals realize a life that exceeds the small circle of our so-called humanity, a full and feral life irreducible to reason and its pale twin, propriety" (1). For a subject that bites back, so to speak, animals prove reliably difficult to pin down. But if they refuse to be boxed into predictable roles, neither can they ever make a clean escape. Then again, neither can we escape from them. And perhaps this is the most critical contribution of Gorgeous Beasts: there is no them and us. Rather all animals - human or otherwise - are co-evolvers, co-habitants, and co-agents. Our fates are utterly entwined.

Besides, neither humanity nor the rest of the animal kingdom has ever been viewed as a homogenous group. In his fascinating chapter, "The Rights of Man and the Rights of Animality at the End of the Eighteenth Century," Pierre Serna unpacks the animals within the rhetoric of revolutionary France. As republican scientists worked to define who precisely was to enjoy the benefits of being "a political animal," the boundaries between so called civilized man, barbarous peoples, inferior classes, and animals were

Humanimalia: a journal of human/animal interface studies

Volume 5, Number 1 (Fall 2013) 
drawn and redrawn in paradoxical ways. Ron Broglio's chapter, "On Vulnerability: Studies from Life that Ought Not to be Copied," examines a different sort of blurring between livestock and human laborers during Britain's eighteenth-century push for agricultural improvements. Farmers have a visceral connection to their animals through their shared daily bodily labor, a connection that Broglio sums up by their mutual vulnerability: "The argument of a shared animality is based not on the animal's capabilities or on that of humans but on a mutual fragility" (87). That fragility becomes more apparent within the resonance of biopower. Flattening any distinction between human and nonhuman animal laborers, biopower hinges their shared existence on statistical estimates, forecasts, and other such governmental technologies. Similarly Sajay Samuel and Dean Bavington examine the interlocked fate of the Grand Banks' fishermen and codfish at the hands of technocratic governmental science which "reduce fishermen's forms-of-life to a form of life" and cod to a statistically declining biomass.

Each in their own way, the essays argue against the adequacy of fixed categories and render distinctions between humans and other animals either meaningless or obsolete. For example in "Renaissance Animal Things," Erica Fudge offers a highly creative analysis on the agency of animal matters - not living animals, but animal products. Fudge proposes the new term "animal-made-object" to signify both an object constructed from an animal and the objectified animal (42). Far from dead materials disconnected from the animals they once were, Fudge shows such animal-made-objects as dog-skin gloves and civet musk to be potent things with the power both to construct and upset notions of being human. In "Calling the Wild" Harriet Ritvo reveals the ostensibly simple terms "wild" and "tame" to be far from the binary opposites they would seem to be, finding "wild" cattle in the Earl of Tankerville's manicured park and "incontestably domesticated" sheep that are upheld as symbolic of their "untamed landscape" (114). Animalizing the human takes a chilling turn in Paul Youngquist's "The Cujo Effect." Youngquist traces the history of the massacre of Jamaica's Maroon warriors in 1795. To quell the Maroon uprising, British army unleashed bloodhounds trained by the Spanish to hunt down and kill escaped slaves. Within the rhetoric of British treaties, the Maroons occupy a middle zone of "animal man" - at once human enough to treat with, but animal enough to hunt. In a remarkable rhetorical twist, Youngquist shows how terror of the animal becomes a racialized sign of savagery.

Gorgeous Beasts is abundantly illustrated with fifty images. The introduction alone has seven images of contemporary animal art (three Amy Stein photographs and four 
works by Dion), and the editors do an excellent job of setting the scene, so to speak, by highlighting the unsettling and unsettled resonance of animal imagery. They begin with one of Stein's photograph - a fox standing in the dark mouth of highway culvert from her Domesticated series. On closer inspection, the portrayal of animal wildness amidst urbanity becomes increasingly convoluted. The fox is taxidermied, which is to say, the fox was already been domesticated to death, already remade into a sign of animal liveliness, before it was used as a photographic prop. Is there any foxiness left? Perhaps not. But as the editors suggest, it does no service to the animal to see it only as human manipulation. After all the power of Stein's image resides quite precisely in the genuine fox that once was. "An image of a fox is a kind of compromise between its life and ours, a mingling of traces that produces a hybrid: neither quite fox nor quite human but something in between"(3). By acknowledging that there are no clear or definitive answers, the editors successfully open the doors to more productive lines of interrogations and a richer play of possibilities.

Although the subtitle of Gorgeous Beasts highlights the volume's historical perspective, considering the introduction's heavy emphasis on contemporary animal art and the closing conversation with Dion, I was astonished (and somewhat disappointed) that only three of the nine essays focus on visual representations of animals and only one takes contemporary animal art as its main subject. In the concluding chapter, Cecilia Novero exposes the dark and deadly play of deceptions underlying conventional ways of seeing animals in Daniel Spoerri's Carnival of Animals (1995) and his use of Le Brun's seventeenth-century animal physiognomies. Nigel Rothfels also does a nice job of connecting historical images with contemporary art. Exploring the appallingly fascinating images of hunters standing on the flanks of dead elephants, Rothfels goes beyond a critique of blatant violence to unpack what precise the hunters are trying to say through such images and why. And Joan B. Landes examines the very different ways in which Comte de Buffon and Pablo Picasso both muddle naturalism and imagination in their beastly images.

For a volume which challenges readers to rethink how they see animals both in historical and contemporary contexts, there are surprising weaknesses in how the images themselves are treated. Some images are not read closely enough while others contribute little to the conversation. For example, Landes notes the human expression of Buffon's orangutan but leaves other aspects of the image unexamined - particularly the grass huts in the distance and the animal's walking stick. Buffon's horse and bull are also presented, and they too have human dwellings in the background, presumably their stables. Is Buffon suggesting that the orangutan likewise lives in the village? And

Humanimalia: a journal of human/animal interface studies

Volume 5, Number 1 (Fall 2013) 
if the ape's expression transfigures him into a hairy human, what about the startlingly direct and intelligent gaze of the horse? Ritvo's discussion of the ancestral Herdwick breed of sheep is accompanied by a 1882 photograph of a champion ram and his owner. The Herdwicks were alleged to have a near mystical connection to their landscape, passing down topographical information generationally. All I see in the photograph is an especially hairy ram and a cantankerous man, and I am not quite sure why I should be looking. However, other images are far more successfully handled, and the most potent in volume is surely another photograph of a man and an animal, this one taken by Carl Akeley in 1896 and included in Rothfels' essay. A dead Somali wild ass lies dead in the dirt; a shadow of Akeley's broad-brimmed hat and torso looms up from the bottom of the photograph, which was taken presumably moments after Akeley shot the animal. The image is jarring, haunting, utterly spellbinding, and cannot but implicate the viewer in the deadly act. That shadow is our shadow.

Of the fifty illustrations, twelve are color plates, and all twelve plates are dedicated to Dion's work. This decision strikes me as especially odd. Why is not at least one of Stein's photograph printed in color? Certainly the discussion of Spoerri's taxidermied foxes would have benefited from a touch of color, if color was to be included. And while Dion's work is deserving of any and all attention, his images become an extraordinary coda as the volume suddenly burst into color when all the talking is done. As Gorgeous Beasts opens and closes with Dion's work, his art almost becomes the lens through which the entire volume is viewed and certainly adds an overarching visual structure to the book.

However, this mishandling of images adds up to a minor criticism of an otherwise thought-provoking and question-filled volume that examines animal as kith and kin, as co-authors and co-inhabitants in an ever-shifting animal world. 